\title{
Ectomycorrhizal communities in a Mediterranean forest ecosystem dominated by Quercus ilex: seasonal dynamics and response to drought in the surface organic horizon
}

\author{
Franck Richard • Melanie Roy • Oula Shahin • \\ Christopher Sthultz $\cdot$ Myriam Duchemin • \\ Richard Joffre $\cdot$ Marc-André Selosse
}

Received: 31 January 2010 / Accepted: 7 June 2010 /Published online: 22 January 2011

(C) The Author(s) 2011. This article is published with open access at Springerlink.com

\begin{abstract}
- Introduction Millions of hectares of Quercus ilex forests dominate disturbed landscapes in the western part of the Mediterranean basin. Although these forests are very widespread, little is known about the composition and structure of their associated ectomycorrhizal fungal communities.

- Results and discussion We examined seasonal patterns in ectomycorrhizal communities and their response to increased drought using a rainfall exclusion experiment established in a $Q$. ilex coppice since 2003. Ectomycorrhizae were sampled four times in 2007-2009. By sequencing fungal ITS, we identified 129 species in 1,147 sequenced ectomycorrhizal root tips. The fungal community in the surface organic horizon was well described by the logseries theoretical model, with $47.9 \%$ of singleton species. The composition of the community was strongly dominated by Basidiomycetes, with three families (Thelephoraceae, Russulaceae and Cortinariaceae) accounting for $72.9 \%$ of the root tips. Relative abundance of Russulaceae and Thelephoraceae showed pronounced seasonal shifts. Experimental reduction of rainfall resulted in significant shifts in community composition and seasonal fluctuations but had no effect on global richness of the community.
\end{abstract}

Handling Editor: Jean Garbaye

Electronic supplementary material The online version of this article (doi:10.1007/s13595-010-0007-5) contains supplementary material, which is available to authorized users.

F. Richard $(\bowtie) \cdot$ M. Roy $\cdot$ O. Shahin $\cdot$ C. Sthultz

M. Duchemin $\cdot$ R. Joffre $\cdot$ M.-A. Selosse

CEFE-CNRS,

1919 Route de Mende,

34293 Montpellier Cedex, France

e-mail: franck.richard@cefe.cnrs.fr
- Conclusions Together, these results suggest that the predicted rainfall reduction in this region due to climate change will lead to shifts in species composition in ectomycorrhizal communities.

Keywords Ectomycorrhizal communities - Global change · Mediterranean forests · Drought

\section{Introduction}

After millennia of exploitation (Quézel and Médail 2003), Mediterranean forests are now facing rapid anthropogenic climate change (IPCC 2007). Current climate models project a rise in mean temperature of between $2.2^{\circ} \mathrm{C}$ and $5.1^{\circ} \mathrm{C}$ and a potential decline of $4-27 \%$ in annual rainfall during the twenty-first century, with dramatic changes in rainfall distribution over the Mediterranean basin (IPCC 2007). According to this scenario, this region may be especially vulnerable, with the extinction of more than 2,000 plant species expected (Malcolm et al. 2006) and dramatic consequences for the structure, dynamics and functioning of Mediterranean forests (Allard et al. 2008). The effects of longer and more severe drought on soil biota are still poorly investigated. From an ecological point of view, a decrease in precipitation may reduce soil wetness (Limousin et al. 2009), decrease soil carbon exchange (Misson et al. 2010) and affect major soil enzymatic activities with consequences for phosphorus, carbon and nitrogen turnover (Barnard et al. 2006; Sardans and Penuelas 2005).

Ectomycorrhizal (ECM) fungi are a key microbial group involved in these soil processes. Like the majority of temperate-zone trees, Mediterranean tree species are associated with these fungi, which make chimeric structures called Ectomycorrhizae on fine roots (Smith and Read 2008). 
More than 5,000 species of Ascomycetes and Basidiomycetes are involved in ectomycorrhizal mutualisms worldwide (Smith and Read 2008). At the ecosystem level, ECM fungi drive nutrient cycling. As in most temperate forests, under the harsh and unpredictable Mediterranean climate, Ectomycorrhizae are crucial for nutrition of both partners and protect plants against soil parasites (Morin et al. 1999), toxic compounds (Hall 2002) and drought (Jany et al. 2002). Understanding and documenting species responses to current and predicted climate change scenarios are current frontiers in ecology (O'Neill et al. 2008; Shi et al. 2002). To our knowledge, the response of ECM fungal communities to the predicted rainfall decline in the Mediterranean basin has not been investigated. More specifically, there is a need to document the effect of increasingly severe drought predicted with climate change on the temporal dynamics of Mediterranean ECM communities.

In the western part of the Mediterranean basin, Quercus ilex L. (holm oak) dominates the landscape at low elevation. This evergreen species covers more than 7.5 Mha, mainly in coppices of anthropogenic origin (e.g. after wildfires or clearcutting), characterized by high stem density and low primary productivity (Terradas 1999). In France, because human pressure on woody resources has decreased, Q. ilex coppices are now expanding and ageing (Scarascia-Mugnozza et al. 2000). As they age, these secondary forests accumulate structural changes that represent new and valuable opportunities for harbouring a diversity of insects, birds and epiphytic bryophytes (see Buse et al. 2008).

To our knowledge, belowground diversity, and especially ECM diversity, has not been studied in $Q$. ilex coppices. During the last decade, molecular studies revealed hyperdiverse ECM assemblages associated with both Californian (Morris et al. 2008; Smith et al. 2007; Walker et al. 2005) and European (Azul et al. 2010; Richard et al. 2005) Mediterranean oaks, but most of this research was carried out in forest systems characterized by low disturbance rates or by only ancient disturbance. None dealt with anthropogenic coppices, despite the dominance of this vegetation type in the Mediterranean area. The sole exception is a preliminary descriptive study of morphotypes of Ectomycorrhizae in presumed species-rich ECM assemblages (de Román and de Miguel 2005). Unfortunately, morphotyping alone does not completely resolve species identification (Horton and Bruns 2001). Knowledge of ECM communities of recently disturbed $Q$. ilex coppices thus remains incomplete.

Because oaks are major hosts of ectomycorrhizal and other fungi in the Mediterranean area, $Q$. ilex coppices are a superb model to test for drought as a potential driving factor underlying structure, composition and temporal dynamics of fungal communities. In this study, we specifically addressed the three following questions using a throughfall exclusion experiment that has been conducted since 2003: (1) What ECM communities are associated with highly disturbed $Q$. ilex coppices? (2) Does the contrasted Mediterranean climate induce seasonal shifts in ECM assemblages? (3) Does simulated rainfall reduction affect ECM richness and diversity in ecosystems dominated by $Q$. ilex?

\section{Material and methods}

\subsection{Study site}

The research site is located $35 \mathrm{~km}$ northwest of Montpellier (southern France) in the Puechabon State Forest $\left(43^{\circ} 44^{\prime}\right.$ $29^{\prime \prime} \mathrm{N}, 003^{\circ} 35^{\prime} 45^{\prime \prime} \mathrm{E}$, elevation $270 \mathrm{~m}$ asl). The state forest covers a 690 -ha area on Jurassic limestone. Soil is shallow with mull humus overlying (1) a superficial (less than $5 \mathrm{~cm}$ on average) organic layer and (2) a mineral horizon of irregular depth (depending on bedrock fissuring) with high clay and high volumetric rock content: $75 \%$ in the first $50 \mathrm{~cm}$ and $90 \%$ for the whole soil profile.

The climate is of Mediterranean type with rainfall mainly occurring during autumn and winter, with about $80 \%$ between September and April. The mean annual precipitation at the study site is $908 \mathrm{~mm}$ with wide variations (from 556 to $1,310 \mathrm{~mm}$ during the period 1984-2008). The average annual temperature is $13.5^{\circ} \mathrm{C}$, ranging from $2.4^{\circ} \mathrm{C}$ (mean January minima) to $28.7^{\circ} \mathrm{C}$ (mean July maxima).

Puechabon State forest is an ancient $Q$. ilex afforestation. This forested area has been managed as a short-rotation (20-25 years) coppice for centuries. The vegetation in the research site is a 66-year-old monospecific $Q$. ilex coppice, with a diffuse ( $<25 \%$ of cover) species-poor understorey, dominated by Buxus sempervirens, Phillyrea latifolia, Ruscus aculeatus and Pistacia terebinthus, overlying a discontinuous herbaceous layer. Of the woody species, only Q. ilex has the ability to associate with ECM fungi (Limousin et al. 2008).

\subsection{Experimental design}

In 2003, a throughfall exclusion experiment was established at the site as part of the European project Mediterranean Terrestrial Ecosystems and Increasing Drought. The experimental design is comparable, in conception, to that described by Hanson et al. (2003). Rainfall exclusion was achieved using PVC gutters covering $33 \%$ of the ground area under the oak canopy. In this experiment, control plots were designed where identical gutters were set up upside down so that the albedo and the micro-climate of the forest understorey 
were the same as those in exclusion plots. The experimental design consisted of three blocks about $50 \mathrm{~m}$ apart, each block comprising two adjacent $140 \mathrm{~m}^{2}(14 \times 10 \mathrm{~m})$ plots (one rainfall exclusion +1 control plot). Given the partitioning of incident rainfall into interception loss, throughfall and stemflow, the throughfall exclusion reduced the average precipitation input to the soil by $29 \%$ (Limousin et al. 2008), as confirmed by significant decrease of soil water potential during summer drought (Limousin et al. 2009). Furthermore, tree physiology was affected, as annual transpiration was reduced by $23 \%$ and predawn leaf water potential was significantly reduced in the dry treatment (Limousin et al. 2009).

\subsection{Sorting and handling of Ectomycorrhizae}

To investigate the temporal dynamics of ECM communities, soil cores (taken with soil cylinders $5.2 \mathrm{~cm}$ in diameter $\times 2.6 \mathrm{~cm}$ depth) were collected at the study site. The organic soil horizon was investigated because it concentrates most of the ECM diversity in general, and it is the most exposed to drought variations. Sampling was conducted twice in autumn (December 2007 and December 2008) and twice in spring (June 2008 and June 2009). These sample dates were chosen based on life history traits of both host and fungi (spring sampling corresponding to the host's photosynthesis maximum (Allard et al. 2008) and autumn sampling corresponding to the fruiting peak of ECM communities).

At each of the four sampling dates, 90 soil cores were collected as follows: three 4-m-long transects were designated in each of the six plots (three control + three exclusion plots). Along each transect, five soil cores were collected at 1-m intervals. Samples were transferred to the laboratory (CEFE, CNRS Montpellier) and stored at $2{ }^{\circ} \mathrm{C}$. Roots were sieved from the soil cores and washed. Short root tips were counted and classified as ECM tips if they possessed a fungal mantle upon examination under a dissecting microscope. All ECM tips were hand-picked and then sorted into morphotypes under a dissecting microscope by characteristics such as colour, shape and distinct features of the mantle (Agerer 2001). In each soil core, a subsample of each morphotype was hand-picked for molecular identification according to the following sampling strategy: (1) one ECM tip for each of the rare morphotypes (i.e. represented by fewer than ten ECM tips) of the core, (2) seven ECM tips for all morphotypes represented by more than ten mycorrhizae in the core and (3) 14 ECM tips for all morphotypes represented by at least 100 ECM tips in the core. Analysis of multiple samples of each morphotype is necessary owing to the richness of ECM communities (Richard et al. 2005).
2.4 Sampling of ECM tips for molecular identification of ectomycorrhizal species

Mycorrhizae of Cenococcum geophilum and those of a dominant Thelephoraceae species (Tomentella sp1), two abundant species representing more than one third of the total number of ECM tips on $Q$. ilex roots, were identified by morphology (de Román and de Miguel 2005; Richard et al. 2005). However, in order to verify their identification, 30 mycorrhizae of each of these two abundant morphotypes were randomly selected from different soil cores and sequenced.

\subsection{Molecular identification of ECM}

ECM tips were rinsed twice in distilled water and stored at $-20^{\circ} \mathrm{C}$ until DNA extraction. Fungal DNA was extracted from ECM tips with the Extract-N-Amp ${ }^{\mathrm{TM}}$ kit (Sigma-Aldrich, St. Louis, USA) with some modifications of the protocol: ECM tips were incubated in $50 \mu \mathrm{L}$ of extraction solution instead of $100 \mu \mathrm{L}$ and diluted in $50 \mu \mathrm{L}$ of dilution solution instead of $100 \mu \mathrm{L}$. The internal transcribed spacer (ITS) region of the rDNA was amplified by polymerase chain reaction (PCR) on $2 \mu \mathrm{L}$ of the freshly extracted DNA, mixed with $10 \mu \mathrm{L}$ of the REDExtract-N-Amp PCR ReadyMix ${ }^{\mathrm{TM}}$ (Sigma-Aldrich, St. Louis, USA), $1 \mu \mathrm{L}$ of each primer at $10 \mu \mathrm{M}$ and $6 \mu \mathrm{L}$ of distilled water (sterilized before mixing by $30^{\prime}$ at $120^{\circ} \mathrm{C}$ in an autoclave and $10^{\prime}$ exposure to UV). PCR products were checked on $1.5 \%$ agarose gel and, when positive, sent to AGOWA Genomics (Warwickshire, UK) for sequencing with the same set of primers used in PCR. All PCR reactions were performed using the primer pair ITS1-F/ITS4 (Gardes and Bruns 1993). A supplementary PCR using the ITS4B primer instead of ITS4 was performed when the first PCR showed two different fungal ITS sequences on the same tip.

Fungal ITS sequences were checked and edited with Sequencher 4.9. Corrected sequences were identified using the BLAST algorithm and the UNITE database (http://unite.ut.ee/). The best BLAST identification was reported for each fungal taxon. The UNITE species name was validated only when (1) the similarity between the submitted sequence and the sequence in the database was higher than $97 \%$ and (2) the UNITE identification made sense when taking into account ecological considerations and known geographical distribution of related species. Sequences with less than $97 \%$ of similarity with the nearest blast, or for which the UNITE species name was considered too uncertain, were ascribed as undetermined species to a genus. Alignments of unnamed sequences were performed at the genus level using ClustalW (Thompson et al. 1994). Between-sequence similarities 
were calculated using BioEdit (Hall 1999) with 97\% similarity as a constant species threshold.

\subsection{Statistical analyses}

Structure of ECM communities was analysed using speciesrelative abundance data. Briefly, Whittaker plots of log abundance on species rank were used to compare the shape of the observed dominance-diversity curves with the geometric series, the $\log$ series, the lognormal and MacArthur's broken-stick theoretical model of species abundance distribution. The observed community data were compared with theoretical distributions using chi-squared goodness-of-fit tests (Krebs 1999).

Comparisons of species richness among ECM communities of different sizes were performed using the rarefaction method as described in Richard et al. (2009). Rarefaction analysis was used to compare (1) spring and autumn and (2) exclusion and control plot richness of ECM communities. For each season and treatment, species diversity within ECM communities was estimated using various indices based on relative abundance of species, including Simpson's diversity index $D$, ShannonWiener information index $H^{\prime}$ (base $2 \operatorname{logs}$ ) and Fisher's alpha.

We analysed the overall community composition of ECM using PRIMER 5 (2002 PRIMER-E Ltd.; Clarke and Gorley 2001) and CAP (Anderson 2004). With PRIMER 5 (2002 PRIMER-E Ltd.; Clarke and Gorley 2001), we performed community analyses of sequences using nonmetric multidimensional scaling, a robust nonparametric analytical technique that is applied to the dissimilarity matrix calculated among sequence types using the Bray-Curtis dissimilarity coefficient based on relative abundances per transect using $\log (x+1)$-transformed data. Soil cores were considered to be independent replicates based on the high degree of patchiness in the belowground occurrence of ECM fungal species in Q. ilex forests (Richard et al. 2005). We used a two-factor analysis of similarity (ANOSIM), which is analogous to an $F$ test where distances or similarities within groups are compared with betweengroup differences to test for the effects of both season and rainfall reduction on structure of ECM community composition. ANOSIM $r$ values measure the strength of these differences and scale between -1 and 1 . Subsequent $P$ values were determined through a randomization procedure. These procedures have been successfully used for the analysis of community composition, including ectomycorrhizal communities (Sthultz et al. 2009).

Using CAP (Anderson 2004), we performed a canonical analysis of principal coordinates, which provides a constrained ordination, followed by a canonical discriminant analysis (CDA), which tests for differences among a priori groups, as described by Anderson and Willis (2003). The test is done by permutation using the trace and first canonical root statistics (Anderson and Willis 2003). We used this secondary technique because often, in ecology, there are several strongly correlated, highly abundant species that do not change across treatment groups. However, there may be patchy, less abundant species that do differ significantly across treatment groups. In this case, CAP will find these differences among the assemblages more often than other tests that do not take into account the correlation structure among the variables. To insure enough replication for proper permutation to be achieved, samples from both years were pooled for these community analyses.

Similarity between ECM communities found in different sampling dates was compared using (1) the binary coefficient of Sorensen, which is based on presence/ absence of species, and (2) the average Euclidian distance based on abundance data (Krebs 1999). Variation in species abundance between seasons and between treatments was tested using chi-squared tests with Yates's correction when necessary. All statistics were considered significant at $P=0.05$.

\section{Results}

Over the four sampling dates, 4,754 ECM tips were sampled, among which 1,574 tips were selected for ITS amplification. Identification was successful for 1,147 ECM tips (73\%; Table 1). The basidiomycete-specific primer pair ITS1-f/ITS4B was used to analyse 22 ECM tips that showed colonization by two different fungal species. In all, 131 species were distinguished. Identification and homogeneity were tested for two dominant morphotypes by sequencing 30 tips for each: these two morphotypes (C. geophilum and Tomentella sp1) proved to be homogeneous.

\subsection{Structure, richness and composition of the ECM communities in control plots}

In control plots, the relative abundances of the ECM species were well described by the log series (Fig. 1). Data showed a typical distribution of individuals per species with $47.9 \%$ of the species (42 out of 94) represented by singletons (first black bar in Fig. 1a) while a lognormal distribution would have been dominated by species of intermediate abundance. Only three species were represented by more than 30 ECM tips (Fig. 1a).

ITS sequencing revealed high species richness in control plots, with 94 species on the $420-\mathrm{m}^{2}$ sampling area, resulting in high values of Shannon-Wiener and Fisher's 
Table 1 Species richness, diversity and heterogeneity estimators of ECM communities at the Puechabon site during the period December 2007June 2009

\begin{tabular}{|c|c|c|c|c|c|c|}
\hline \multirow[t]{2}{*}{ Parameter } & \multicolumn{3}{|l|}{ Control plots } & \multicolumn{3}{|c|}{ Rainfall exclusion plots } \\
\hline & Spring & Autumn & Total & Spring & Autumn & Total \\
\hline Number of species ${ }^{a}$ & $40.5(154.5)$ & $37(122)$ & $61.5(276.5)$ & $37.5(153)$ & $36(144)$ & $60.5(297)$ \\
\hline Rarefied number of species ${ }^{\mathrm{b}}$ & $28.8(81)$ & $30.4(81)$ & $93.3(541)$ & $27.1(81)$ & $27(81)$ & $88.8(541)$ \\
\hline Fisher's alpha ${ }^{c}$ & 18.32 & 17.88 & 24.39 & 16.31 & 15.99 & 23.53 \\
\hline Simpson's (1-D) index of diversity ${ }^{\mathrm{c}}$ & 0.92 & 0.91 & 0.92 & 0.92 & 0.91 & 0.94 \\
\hline Shannon-Wiener information index $\left(\mathrm{H}^{\prime}\right)^{\mathrm{c}}$ & 4.36 & 4.27 & 4.74 & 4.29 & 4.21 & 5.04 \\
\hline Total number of sampled ECM tips & 309 & 244 & 553 & 306 & 288 & 594 \\
\hline
\end{tabular}

${ }^{a}$ Values are mean numbers of species per sampling years ( $n=2$ consecutive years) with mean numbers of ECM tips per sampling year within parentheses

${ }^{\mathrm{b}}$ Rarefaction analyses were conducted on spring and autumn communities in control and rainfall exclusion plots on the one hand (minimal sample size $n=81$ root tips) and on total communities in control and rainfall exclusion plots on the other hand (minimal sample size $n=541$ root tips)

${ }^{\mathrm{c}}$ Values of diversity and heterogeneity estimators are mean numbers per sampling years ( $n=2$ consecutive years)

alpha diversity estimators (Table 1). The Simpson index revealed a probability of $92 \%$ that two ECM tips picked at random within the community belong to two different species (Table 1).
The ECM community was strongly dominated by Basidiomycetes $(83.7 \%$ of ECM tips, and $85.7 \%$ of species; Fig. 2). At the family level, three distinct patterns were found: (1) three abundant and species-rich families,

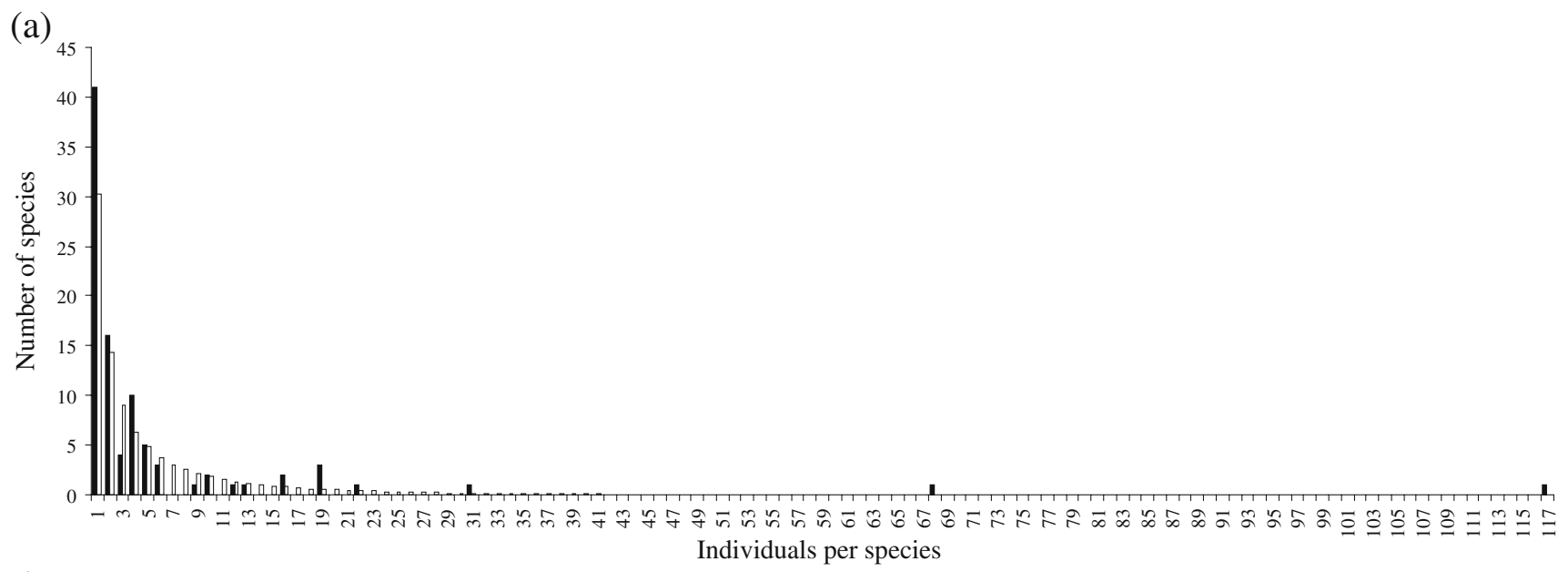

(b)

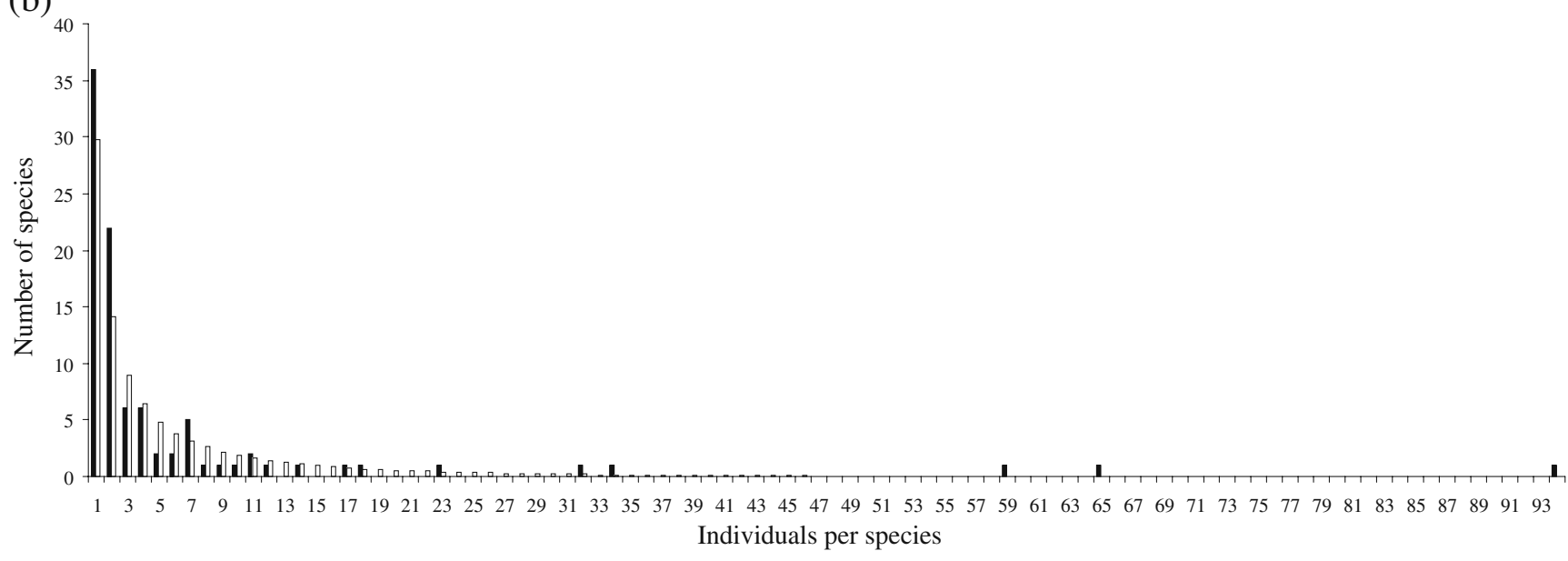

Fig. 1 Observed (black bars) and log series theoretical (white bars) distributions of ECM taxa according to their abundance classes as observed at Puechabon from December 2007 to June 2009 in control (a) and rainfall exclusion (b) plots 
Fig. 2 Ratio between Ascomycete (black) and Basidiomycete (white) lineages at Puechabon in control (a) and rainfall exclusion (b) plots, with details of Ascomycete families (for details of Basidiomycetes, see Fig. 5b). Values are relative importance of both lineages expressed in percent. The numbers of ECM tips (i.e. abundance data) and total numbers of ECM tips are within parentheses
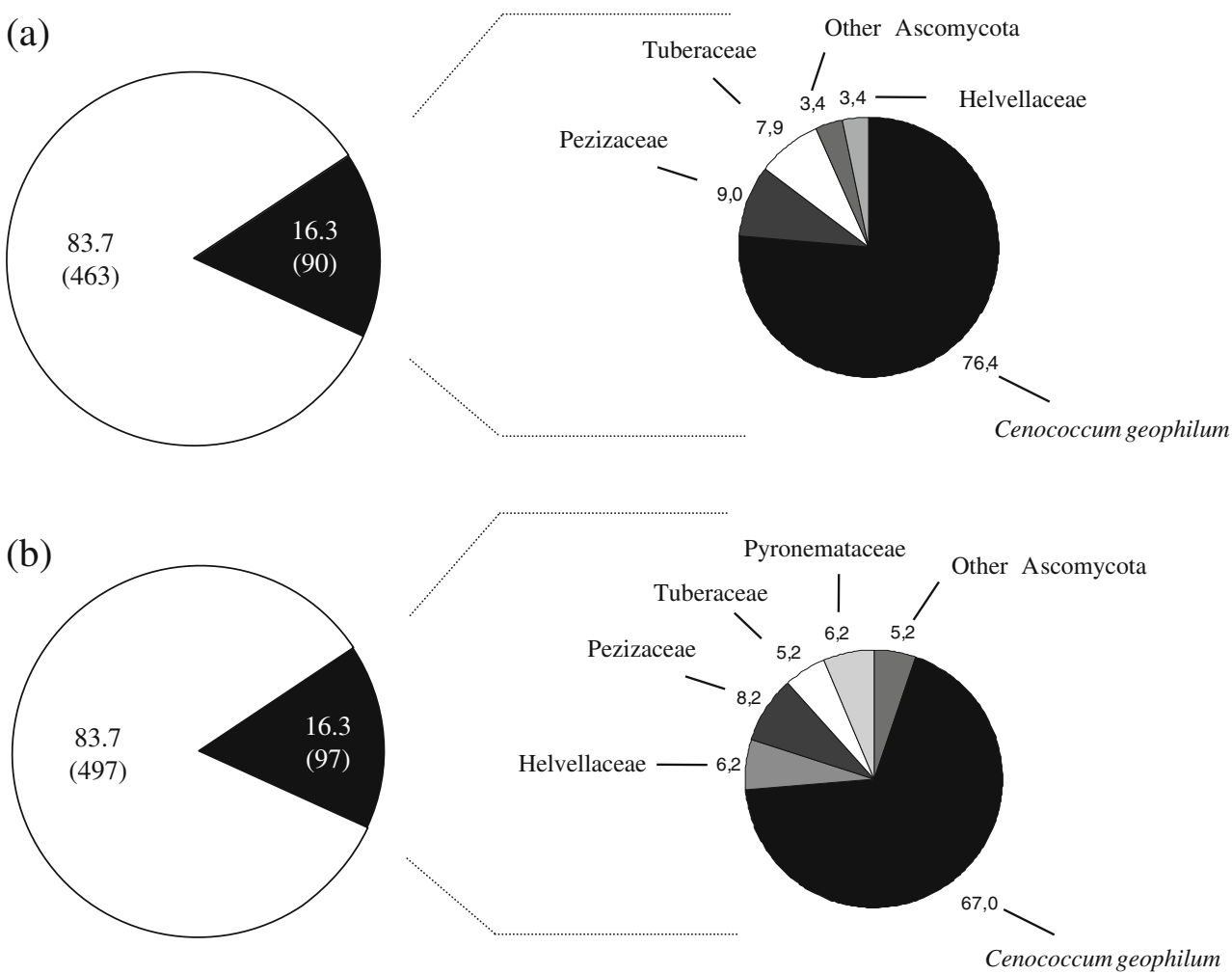

Thelephoraceae, Russulaceae and Cortinariaceae, accounted for $72.9 \%$ of the root tips and $70.3 \%$ of species, (2) two moderately abundant and species-poor groups, Sebacinaceae and $C$. geophilum accounted for $19.8 \%$ of the root tips but only $4.3 \%$ of the species, and (iii) ten rare families together represented $7.3 \%$ of the root tips and $25.4 \%$ of the species (Table 2). With $35.5 \%$ of the ECM tips, Thelephoraceae was the most abundant family, and with $28.7 \%$ of the total number of ECM taxa, Cortinariaceae was the most speciesrich (Table 2).

At the species level, while the asexual taxon C. geophilum strongly dominated among Ascomycetes (Fig. 2a), while Tomentella sp1 represented $35.3 \%$ of the Basidiomycete ECM tips (data not shown). Moderately abundant species included Inocybe grisealilacina, Sebacina epigaea, Lactarius acerrimus, Russula faustiana and Thelephora caryophyllea, which together accounted for $19.9 \%$ of ECM tips. The 45 singleton species mainly encompassed Cortinariaceae (28.9\%; 13 species), Russulaceae (22.2\%; eight species) and Tuberaceae (11.1\%; five species).

3.2 Temporal variation of the ECM communities in control plots

Only $8.5 \%$ of the ECM species (eight out of 94) were found in all four sampling dates (Fig. 3a). These species represented $55.7 \%$ of the total number of root tips (Fig. 3a) and were among the 15 most abundant species (ranks 1, 2, 4-7, 12 and 15). In contrast, 61.7\% of species (58 out of 94) were found at only one of the four sample dates (Fig. 3a). Most of these species were not abundant, and together, they accounted for only $15.7 \%$ of total root tips (Fig. 3a).

Similarity between pairs of consecutive sampling dates, as calculated using either the Sorensen binary coefficient or Euclidian distance, showed similar patterns (Fig. 4). The lowest similarity level (i.e. greatest distance) was obtained when comparing June 2008 and December 2008 communities. These two consecutive seasons shared the lowest number of species of any pair in the whole sampling period (Fig. 4). Similarity between the first (December 2007) and the last sampling date (June 2009) was higher than any of the three pairs of consecutive seasons when using presence/ absence data (i.e. species turnover; Fig. 4).

Spring and autumnal relative abundances of ECM species both fitted to a $\log$ series theoretical distribution (data not shown). Rarefied values of species richness averaged 28.8 and 30.4 in spring and fall, respectively (Table 1). Similarly, values of Fisher's alpha and Simpson and Shannon-Wiener indexes tended to be higher in spring than in autumn (Table 1).

Overall, season did not have a significant impact on community composition of ECM species in control plots (ANOSIM $r=0.005, P=0.353$ ). This was also true for the CDA test in CAP (trace statistic $=0.542, P=0.128$ ). Only three ECM families (out of 14) and four species (out of 94) 
Table 2 Temporal distribution of ECM families, including details of related species with significantly contrasted patterns, at the Puechabon site in control plots from December 2007 to June 2009

\begin{tabular}{|c|c|c|c|}
\hline \multirow[t]{2}{*}{ Parameter } & \multicolumn{3}{|c|}{ Sampling period } \\
\hline & Autumn & Spring & Total \\
\hline $\begin{array}{l}\text { Thelephoraceae } \\
\text { Thelephora caryophyllea }\end{array}$ & $\begin{array}{r}41.9 \mathrm{a} \\
7.0 \mathrm{a}\end{array}$ & $\begin{array}{r}30.0 \mathrm{~b} \\
0.7 \mathrm{~b}\end{array}$ & 35.5 \\
\hline Cortinariaceae & $17.1 \mathrm{a}$ & $16.5 \mathrm{a}$ & 16.7 \\
\hline $\begin{array}{l}\text { Russulaceae } \\
\text { Russula } \mathrm{sp} 1\end{array}$ & $\begin{array}{r}15.0 \mathrm{a} \\
0.4 \mathrm{a}\end{array}$ & $\begin{array}{r}25.2 \mathrm{~b} \\
3.9 \mathrm{~b}\end{array}$ & 20.7 \\
\hline Russula faustiana & $2.0 \mathrm{a}$ & $4.6 \mathrm{~b}$ & \\
\hline Lactarius acerrimus & $0.4 \mathrm{a}$ & $5.9 \mathrm{~b}$ & \\
\hline Cenococcum geophilum & $12.6 \mathrm{a}$ & $11.9 \mathrm{a}$ & 12.2 \\
\hline Sebacinaceae & 6.9 a & $8.1 \mathrm{a}$ & 7.6 \\
\hline Pezizaceae & $2.8 \mathrm{a}$ & $0.3 \mathrm{~b}$ & 1.4 \\
\hline Tuberaceae & $1.2 \mathrm{a}$ & $1.3 \mathrm{a}$ & 1.3 \\
\hline Tricholomataceae & $0.8 \mathrm{a}$ & $1.9 \mathrm{a}$ & 1.4 \\
\hline Albatrellaceae & $0.4 \mathrm{a}$ & $1.0 \mathrm{a}$ & 0.7 \\
\hline Hygrophoraceae & $0.4 \mathrm{a}$ & $0.6 \mathrm{a}$ & 0.5 \\
\hline Sclerodermataceae & $0.4 \mathrm{a}$ & $1.0 \mathrm{a}$ & 0.7 \\
\hline Clavulinaceae & $0 \mathrm{a}$ & $0.3 \mathrm{a}$ & 0.2 \\
\hline Helvellaceae & $0 \mathrm{a}$ & $1.0 \mathrm{a}$ & 0.5 \\
\hline Melanogastraceae & $0 \mathrm{a}$ & $0.3 \mathrm{a}$ & 0.2 \\
\hline Other Ascomycotina & $0.4 \mathrm{a}$ & $0.6 \mathrm{a}$ & 0.5 \\
\hline
\end{tabular}

Values are relative abundances of families and species (expressed as the percentage of the total number of sequenced tips). Values followed by different letters significantly differ according to chi-squared tests with Yates's corrections

showed significant differences between spring and autumn. While Thelephoraceae $\left(\chi^{2}=8.75 ; P<0.01\right)$ and Pezizaceae $\left(\chi^{2}=4.51 ; P<0.05\right)$ were more represented in autumn, members of Russulaceae $\left(\chi^{2}=16.7 ; P<0.001\right)$ were significantly more represented in spring soil samples (Table 2 ). One species, T. caryophyllea, was tenfold more abundant in autumn (rank 3) than in spring (rank 24; Fig. $3 b$ and Table 2). Conversely, three species were more common in spring than in autumn, L. acerrimus (rank 3 vs. 33), $R$. faustiana (rank 5 vs. 8) and Russula sp1 (rank 7 vs. 34) (Table 2). These four species represented $12.6 \%$ of the total number of ECM tips (Fig. 3c). The 90 remaining species were (1) either too rare to show any significant seasonal pattern $(69.2 \%$ of species, accounting for $20.1 \%$ of ECM tips) or (2) indifferently sampled in both seasons $(26.5 \%$ of species, including C. geophilum, accounting for $67.3 \%$ of ECM tips; Fig. 3b, c).

\subsection{Effect of simulated drought on ECM communities}

Whittaker plots of log abundance on species rank showed very similar distributions of species-relative abundances in control and water exclusion plots, both dominated by rare taxa with very few abundant ones. Water exclusion had no effect on species richness: rarefied values of species richness averaged 93.3 and 88.8 out of 541 individuals in control and water exclusion plots, respec-

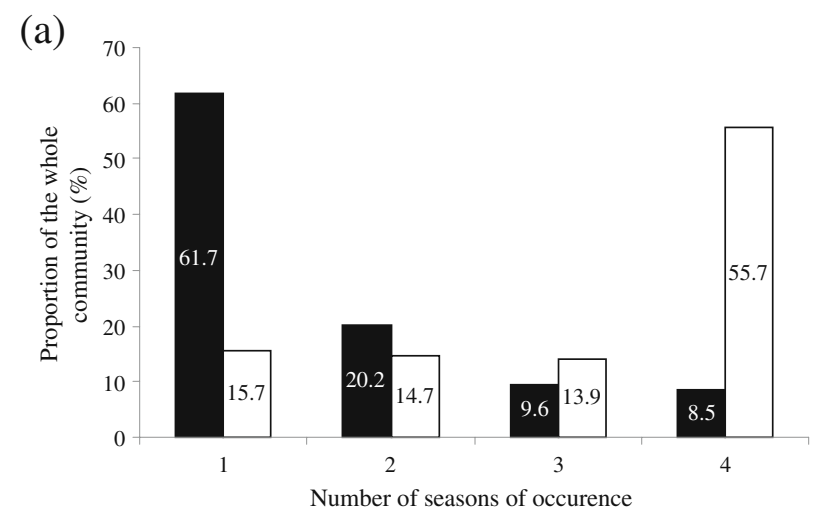

(b)

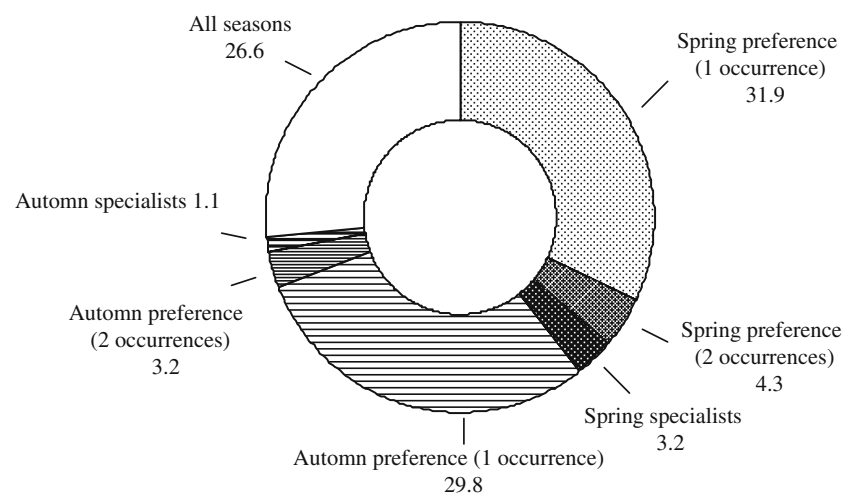

(c)

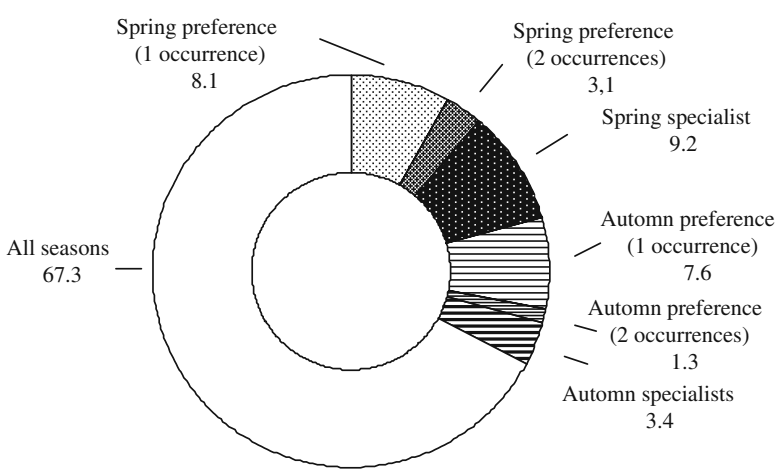

Fig. 3 Temporal distribution of ECM diversity at Puechabon in control plots from December 2007 to June 2009. a Distribution of frequencies of ECM taxa (i.e. sampled once vs. twice vs. three vs. four different periods) expressed using either number of taxa (black bars) or numbers of ECM tips (white bars). b, c Distribution of ECM taxa according to their phenological patterns, based on occurrence (b) and abundance (c) data: seasonal specific taxa are sampled only in spring or only in fall, with no significant difference in abundance; seasonal preferential taxa are mainly sampled during spring or fall, with significant difference in abundance; all season taxa are indifferently sampled in spring and fall, with no significant difference in abundance. Values are expressed in percentages of the whole community 
Fig. 4 Diagrammatic representation of temporal variation in the composition of ECM communities at Puechabon from December 2007 to June 2009. Numbers are values of the Sorensen similarity coefficients, with Euclidian distances within parentheses, calculated between pairs of sampling seasons. Black arrows indicate sampling dates, with indication of the different seasons as follows: spring (white), summer (light grey), fall (dark grey) and winter (black)

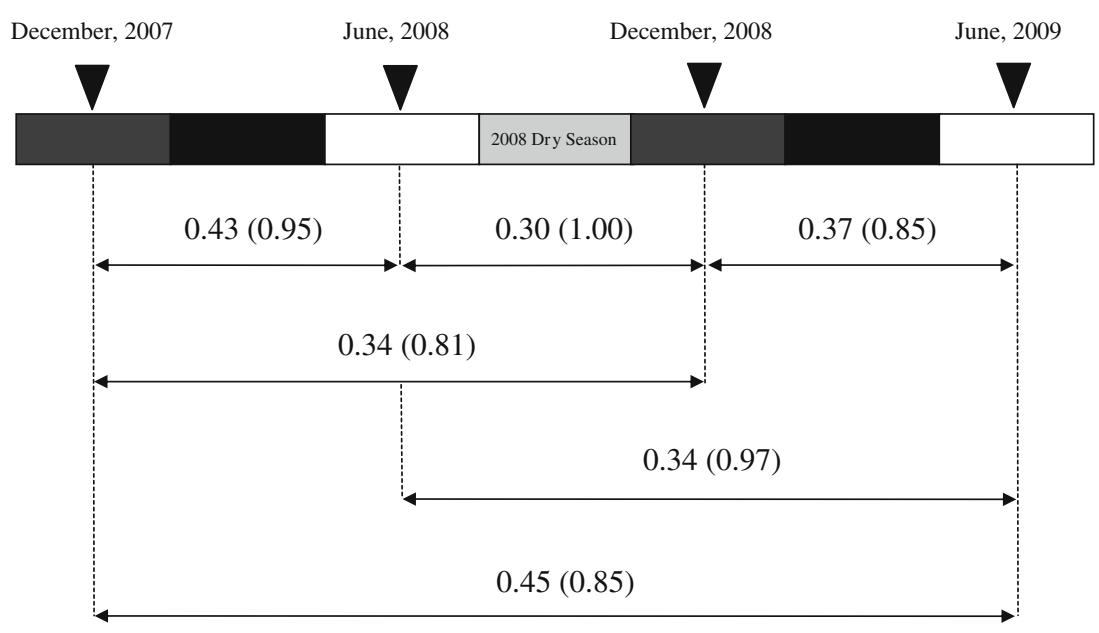

tively (Table 1), when averaged across all four sampling dates. Species diversity did not differ between treatments (Table 1). Similarly, values of Simpson and ShannonWiener indices differed only slightly between experimental plots (Table 1).

The rainfall reduction treatment significantly altered ECM community composition (ANOSIM $r=0.043, P=$ 0.014 ; Fig. 5a). The communities from spatially distinct blocks of the same treatment also differed, but the treatment had more effect than the distance on composition of ECM communities (Fig. 5a). The results of the CDA support this finding and show significant differences between the control and experimental water exclusion plots (trace statistic $=1.516, P=0.001)$. The CDA in CAP showed that season had a significant effect on ECM community composition in the experimental water removal plots (trace
Fig. 5 Effect of drought on ECM communities. a A canonical analysis of principal coordinates ordination of ECM community composition of control (grey shapes) and rainfall exclusion (white shapes) plots during spring (circles) and fall (triangles). Each point represents the ECM community of a single transect in either block 1 (solid lines), block 2 (small dashes) or block 3 (large dashes). b Relative abundance at the family level in control (black bars) and rainfall exclusion (white bars) plots. An asterisk above a pair of bars indicates a significant difference $(P<0.05)$ between control and exclusion plots for the corresponding ECM family as tested using a chi-squared test (a)

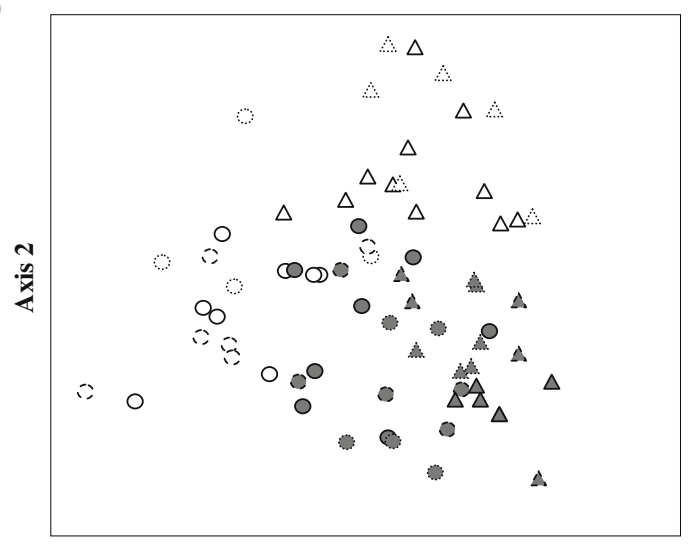

Axis 1

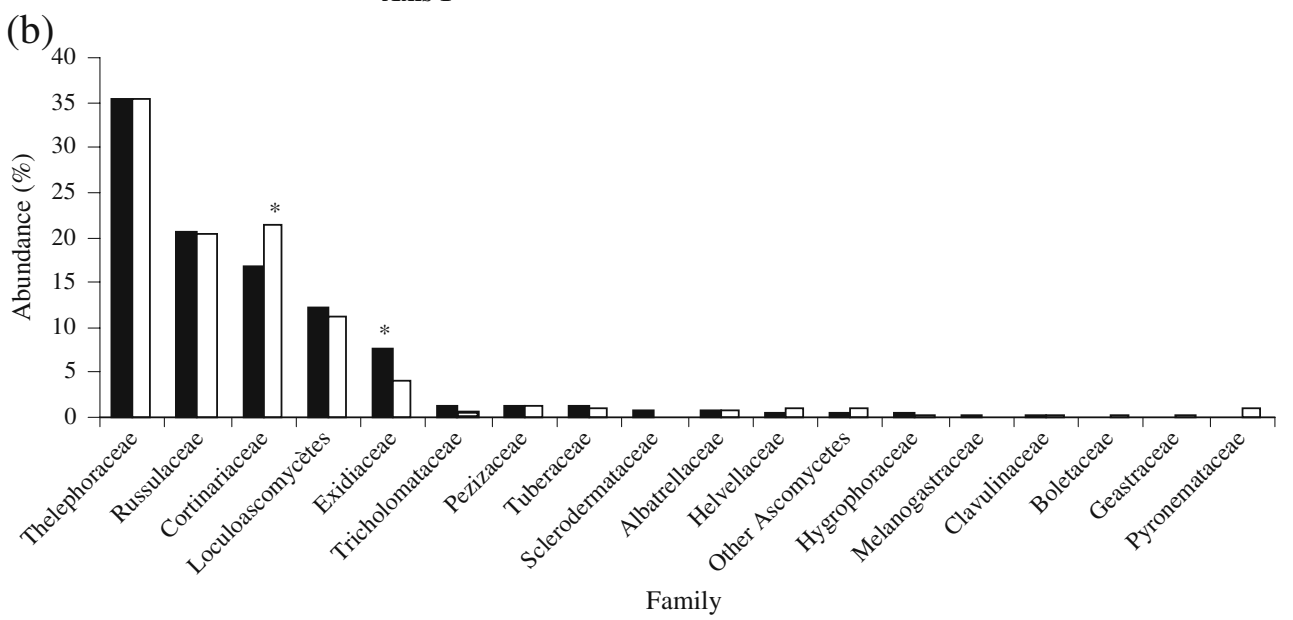


statistic $=0.689, P=0.017$; Fig. 5a). The results from the two-factor ANOSIM and the CDA in CAP show that ECM assemblages in this study consist of three distinct communities; one associated with the control plots in both spring and autumn, one associated with water exclusion plots in spring and finally one associated with water exclusion plots in autumn (Fig. 5a).

Rainfall reduction had a moderate effect on composition of the ECM community. In both treatments, Ascomycetes accounted for $16.3 \%$ of the total number of root tips (Fig. 2a, b). The asexual C. geophilum was the most abundant Ascomycete species, accounting for more than two thirds of root tips $(76.4 \%$ and $67 \%$ in control and water exclusion plots, respectively; Fig. 2a, b).

The same four families of Basidiomycetes as in control plots strongly dominated in water exclusion plots (i.e. Thelephoraceae, Cortinariaceae, Russulaceae and Sebacinaceae; Fig. 5b). Only two families showed a significant difference in abundance between treatments: in water exclusion plots, Cortinariaceae $\left(\chi^{2}=7.83 ; P<\right.$ 0.01 ; rank 3 in control and rank 4 in water exclusion plots) were significantly more abundant, while members of Sebacinaceae $\left(\chi^{2}=6.19 ; P<0.02\right.$; rank 5 in both treatments) were less represented (Fig. 5b).

In all, only six species (out of $129,4.7 \%$; e.g. three species of Cortinariaceae, as well as Tomentella lilacinogrisea, Russula maculata and Humaria hemisphaerica) increased significantly in abundance in water exclusion plots (Table 3 ). Three of them, namely $R$. maculata, $T$. lilacinogrisea and Hebeloma velutipes, were among the ten most abundant species of the community. Inversely, seven species (5.4\%; three Russulaceae, two Thelephoraceae, Inocybe hirtella and Sebacina incrustans) were significantly more represented in control plots (Table 3). Two of these, R. faustiana and L. acerrimus, were among the ten most abundant species. The 116 remaining species were either unaffected (for 16 of them, including Tomentella $\mathrm{sp} 1$ and $C$. geophilum) by the water reduction or too rare (for 102 of them) to be submitted to any statistical test (Table 3).

\section{Discussion}

4.1 Structure and richness of ECM communities in Q. ilex coppices

The structure of ECM fungal assemblages of $Q$. ilex coppices is similar to that of communities previously described in $Q$. ilex old-growth stands (Richard et al. 2005 ) in that it harbours a high species richness (Table 1) and is dominated by rare taxa (Figs. 1 and 3a). This was quite unexpected when considering the features of the stand. The duration and intensity of human pressure in the

Table 3 Variation in abundance between control and rainfall exclusion plots for the 29 most abundant ECM species at the Puechabon site from December 2007 to June 2009

\begin{tabular}{|c|c|c|c|}
\hline \multirow[t]{2}{*}{ Family or fungal group } & \multicolumn{2}{|l|}{ Species with a higher abundance in } & \multirow{2}{*}{$\begin{array}{l}\text { Species with no change in } \\
\text { abundance }\end{array}$} \\
\hline & Rainfall exclusion & Control & \\
\hline Thelephoraceae & Tomentella lilacinogrisea*** & $\begin{array}{l}\text { Tomentella subtestacea*** } \\
\text { Tomentella coerulea* }\end{array}$ & $\begin{array}{l}\text { Tomentella sp } \\
\text { Thelephora caryophyllea } \\
\text { Tomentella bryophila } \\
\text { Tomentella badia } \\
\text { Tomentella subclavigera } \\
\text { Tomentella stuposa }\end{array}$ \\
\hline Cortinariaceae & $\begin{array}{l}\text { Hebeloma velutipes** } \\
\text { Cortinarius torvus* } \\
\text { Cortinarius tenuiores group } \mathrm{sp}^{*}\end{array}$ & Inocybe hirtella** & $\begin{array}{l}\text { Inocybe griseolilacina } \\
\text { Inocybe flocculosa } \\
\text { Cortinarius neofurvolaesus } \\
\text { Cortinarius hinnuleus }\end{array}$ \\
\hline Russulaceae & Russula maculata*** & $\begin{array}{l}\text { Russula } \mathrm{sp} 1^{* * *} \\
\text { Russula faustiana** } \\
\text { Lactarius acerrimus** }\end{array}$ & $\begin{array}{l}\text { Lactarius subserifluus } \\
\text { Russula } \mathrm{sp} 2 \\
\text { Russula vinosobrunnea }\end{array}$ \\
\hline Sebacinaceae & & Sebacina incrustans ${ }^{* * *}$ & Sebacina epigaea \\
\hline Pyronemataceae & Humaria hemisphaerica*** & & \\
\hline Other Ascomycotina & & & Cenococcum geophilum \\
\hline Pezizaceae & & & Hydnobolites cerebriformis \\
\hline
\end{tabular}

Significant differences between treatments using chi-squared tests with Yates's correction: $* P<0.05 ; * * P<0.01 ; * * * P<0.001$ 
Mediterranean region, which dramatically eroded plant communities in Mediterranean oak coppices, leading to loss of some ECM hosts (Quézel and Médail 2003), could be expected to affect ECM communities. Similar current agro-sylvo-pastoral exploitation leads to impoverishment of ECM fungal assemblages, for instance in $Q$. suber Montados (Azul et al. 2010). Our result may reflect a long recovery process of ECM diversity in coppices (associated with forest ageing), the signature of ancient human pressure in $Q$. ilex old-growth stands or both. In any of these cases, the high ECM richness observed in our studied system suggests that these highly humandisturbed ecosystems may still be valuable reservoirs of fungal diversity.

The strong dominance of rare taxa is striking when the moderate age of the studied coppice is considered. When taking into account the natural dynamics of $Q$. ilex forests, a 66-year-old coppice corresponds to a mid-stand development. Previous studies, based on either fruiting bodies (Visser 1995) or root tips (Baxter et al. 1999), showed that ECM species abundance distribution in forests of middle age becomes lognormal, while the distribution we observed fits to the log series model (Fig. 1). This may suggest that our sampling effort was insufficient to detect many rare taxa. However, the dominance of rare taxa occurs in species-rich ECM assemblages of old sampled stands (old-growth stage; O'Dell et al. 1999; Richard et al. 2005; Smith et al. 2002). The ECM communities may thus reflect more the age of the tree individuals (age of root systems) than the age of stems since the last clear-cut. This is in line with observations in Fagus sylvatica coppices of various ages resprouting from stumps of same age, where ECM richness and evenness do not vary with stem age (di Marino et al. 2009).

\subsection{Temporal variation of ECM communities}

Despite the strong seasonality of the Mediterranean climate, both composition and richness of ECM communities at Puechabon were remarkably insensitive to the period of sampling (Table 1). Season had no significant effect on the composition of the overall community (Fig. 5a) and only induced significant shifts in abundance of three ECM families (Table 2) and four species (Fig. 3). Our results differ from those of most recent studies showing marked seasonal dynamics within ECM assemblages (Buée et al. 2005; Courty et al. 2008; Koide et al. 2007). However, these studies were carried out in temperate or montane climatic contexts. The first report on temporal dynamics of ECM communities in Mediterranean forests is consistent with our results: in xeric Quercus douglasii woodland, Smith et al. (2007) described a stable ECM community across seasons.
In our studied system, Thelephoraceae (more abundant in autumn) and Russulaceae (more abundant in spring), which collectively made up more than $50 \%$ of the ECM tips and more than $40 \%$ of species, showed opposite patterns of temporal abundance (Table 2). Interestingly, they also have contrasted fruiting patterns in $Q$. ilex coppices: while Thelephoraceae preferentially fruit in late winter and spring, Russulaceae (mostly Russula species) are autumnal fruiters (Chevassut 1988). These ECM families may decouple in time their vegetative and sexual reproductive investments in this ecosystem. The observed difference also suggests that the period of maximum investment in mycelial growth may contribute to delineation of the ecological niche. As previously shown for soil micro-organisms (Smit et al. 2001) including ECM fungi (Koide et al. 2007), temporal partitioning, by reducing interspecific competition, may be a mechanism underlying the maintenance of (1) a high species richness within the community at local scale and (2) the striking dominance of the family Thelephoraceae in $Q$. ilex forests (de Román and de Miguel 2005).

\subsection{Impact of increased drought on ECM communities}

Our results suggest that five consecutive years of increased drought (1) induced significant shifts in the composition and (2) enhanced the seasonal dynamics of ECM assemblages in $Q$. ilex coppices (Fig. 5a) but (3) did not cause any decrease in species richness or diversity (Table 1).

The first response (shifts in species composition) suggests that the main consequence of an extended drought may be qualitative, including variation in relative abundance for dominant fungal species (Table 3) and families (Fig. 5b). Pronounced changes in ECM community composition following severe drought have been previously reported in Pinus edulis forests, including an increase in relative abundance of Ascomycetes (Sthultz et al. 2009; Swaty et al. 2004). Our data show that in the richer ECM communities associated with $Q$. ilex, drought leads neither to change in the Ascomycetes to Basidiomycetes ratio nor to an increase in the relative abundance of the dominant species C. geophilum (Fig. 2) but does lead to a positive response of the family Cortinariaceae (Fig. 5 b and Table 3 ). This is not the first report of drought resistance in Cortinariaceae species. Using activity profiling of excised ECM root tips, Buée et al. (2005) showed drought resistance traits for three Cortinariaceae species, such as higher abundance and metabolic activity in summer as compared with winter. Other adaptive traits may contribute, including differential tradeoff between vegetative and reproductive investments (for instance, most Cortinarius species fruit only erratically in $Q$. ilex forests (Chevassut 1988)) to maintain abundance and richness of Cortinariaceae in the context of increased drought. The absence of response of 
C. geophilum to drought is more surprising, since it has been previously described as an efficient root protectant against drought (di Pietro et al. 2007) as well as a droughttolerant fungal species (Jany et al. 2003).

Our results also suggest that the expected changes in rainfall distribution in the French Mediterranean region may induce seasonal variation in the composition of ECM communities (Fig. 5a). The mechanisms underlying these shifts may include responses of both trees and ECM symbionts. For instance, ecophysiological adaptations of forest trees to drought, such as reduced fine root production (Valdes et al. 2006), may in turn drive fungal shifts. Similarly, ECM symbionts unequally survive drying under controlled conditions (di Pietro et al. 2007).

The third response (no decrease in species richness and diversity) was not expected and deserves further investigation. This result contrasts with previous reports of a significant decrease in ECM species richness for $P$. edulis forests suffering a decade-long drought (Sthultz et al. 2009). Several reasons, not mutually exclusive, may account for these discrepancies. First, the frequent natural fluctuations of the Mediterranean climate may have already selected for ECM species able to survive short periods of drought. Second, in the previous framework, the artificial 5-year disturbance may be insufficient in duration and/or intensity of drought to induce a dramatic loss of species in these highly adapted communities. Third, the high species richness of $Q$. ilex ECM assemblages (especially as compared with Pinus ECM assemblages) may limit the detection of rare species and the related local extinction events.

From a biological point of view, the observed oscillations in relative abundance of ECM species may reflect changes in vegetative dynamics within the ECM assemblages, with unknown effects on population structures. However, the long-term effect, if any, of the increased variations remains to be investigated.

Acknowledgements This study is part of FUNDIV Grant (ANR606BDIV-06) funded by the ANR. We are grateful to Dr. J.M. Ourcival, who helped us collect field data. This paper is dedicated to the memory of our colleague Dr. Laurent Misson, who participated in this project before being unjustly taken, on March 3, 2010. All the experiments performed in this study comply with the current laws of France.

Open Access This article is distributed under the terms of the Creative Commons Attribution Noncommercial License which permits any noncommercial use, distribution, and reproduction in any medium, provided the original author(s) and source are credited.

\section{References}

Agerer R (2001) Exploration types of Ectomycorrhizae. Mycorrhiza $11: 107-114$

Allard V, Ourcival J-M, Rambal S, Joffre R, Rocheteau A (2008) Seasonal and annual variation of carbon exchange in an evergreen Mediterranean forest in southern France. Glob Change Biol 14:1-12

Anderson MJ (2004) CAP: a FORTRAN computer program for canonical analysis of principal coordinates. Department of Statistics, University of Auckland, New Zealand

Anderson MJ, Willis TJ (2003) Canonical analysis of principal coordinates: a useful method of constrained ordination for ecology. Ecology 84:511-525

Azul AM, Sousa JP, Agerer R, Martín MP, Freitas H (2010) Land use practices and ectomycorrhizal fungal communities from oak woodlands dominated by Quercus suber L. considering drought scenarios. Mycorrhiza 20:73-88

Barnard R, Le Roux X, Hungate BA, Cleland EE, Blankinship JC, Barthes L, Leadley PW (2006) Several components of global change alter nitrifying and denitrifying activities in an annual grassland. Funct Ecol 20(4):557-564

Baxter JW, Pickett STA, Carreiro MM, Dighton J (1999) Ectomycorrhizal diversity and community structure in oak forest stands exposed to contrasting anthropogenic impacts. Can J Bot 77:771-782

Buée M, Vairelles D, Garbaye J (2005) Year-round monitoring of diversity and potential metabolic activity of the ectomycorrhizal community in a beech (Fagus sylvatica) forest subjected to two thinning regimes. Mycorrhiza 15:235-245

Buse J, Levanony T, Timm A, Dayan T, Assmann T (2008) Saproxylic beetle assemblages of three managed oak woodlands in the Eastern Mediterranean. Zool Middle East 45:55-66

Chevassut G (1988) Premiers résultats de l'étude écologique et coenologique des macromycètes de la chênaie verte méditerranéenne française (Quercetum ilicis Gallo-provinciale). Bull Soc Mycol Fr 104(2):73-78

Clarke KR, Gorley RN (2001) PRIMER v5: user manual/tutorial. PRIMER-E, Plymouth

Courty PE, Franc A, Pierrat JC, Garbaye J (2008) Temporal changes in the ectomycorrhizal community in two soil horizons of a temperate oak forest. Appl Environ Microb 74(18):5792-2801

de Román M, de Miguel AM (2005) Post-fire, seasonal and annual dynamics of the ectomycorrhizal community in a Quercus ilex L. forest over a 3-year period. Mycorrhiza 15:471-482

Di Marino E, Montecchio L, Scattolin L, Abs C, Agerer R (2009) The ectomycorrhizal community structure in European beech forests differing in coppice shoot age and stand features. J Forest 107 (5):250-259

Di Pietro M, Churin JL, Garbaye J (2007) Differential ability of ectomycorrhizas to survive drying. Mycorrhiza 17:547-550

Gardes M, Bruns TD (1993) ITS primers with enhanced specificity for basidiomycetes-application to the identification of mycorrhizae and rusts. Mol Ecol 2:113-118

Hall TA (1999) BioEdit: a user-friendly biological sequence alignment editor and analysis program for windows 95/98/NT. Nucleic Acids Symp Ser 41:95-98

Hall JL (2002) Cellular mechanisms for heavy metal detoxification and tolerance. J Exp Bot 53(366):1-11

Hanson PJ, Todd DE, Huston MA (2003) Walker branch throughfall displacement experiment (TDE). In: Hanson PJ, Wullschleger SD (eds) North American temperate deciduous forest responses to changing precipitation regimes, ecological studies, vol 166. Springer, New York, pp 8-31

Horton TR, Bruns TD (2001) The molecular revolution in ectomycorrhizal ecology: peeking into the black-box. Mol Ecol 10:1855-1871

IPCC (2007) Climate change 2007: the physical science basis. Contribution of Working Group I to the Fourth Assessment Report of the Intergovernmental Panel on Climate Change. Cambridge University Press, Cambridge

Jany JL, Garbaye J, Martin F (2002) Cenococcum geophilum populations show a high degree of genetic diversity in beech forests. New Phytol 154(3):651-659 
Jany JL, Martin F, Garbaye J (2003) Respiration activity of ectomycorrhizas from Cenococcum geophilum and Lactarius sp. in relation to soil water potential in five beech forests. Plant Soil 255:487-494

Koide RT, Durland L, Shumway DL, Xu B, Sharda JN (2007) On temporal partitioning of a community of ectomycorrhizal fungi. New Phytol 174:420-429

Krebs CJ (1999) Ecological methodology. Benjamin Cummings, Menlo Park, p 574

Limousin JM, Rambal S, Ourcival JM, Joffre R (2008) Modelling rainfall interception in a Mediterranean Quercus ilex ecosystem: lesson from a throughfall exclusion experiment. J Hydrol 357(1-2):57-66

Limousin JM, Rambal S, Ourcival JM, Rocheteau A, Joffre R, Rodriguez-Cortina R (2009) Long-term transpiration change with rainfall decline in a Mediterranean Quercus ilex forest. Glob Change Biol 15(9):2163-2175

Malcolm JR, Liu C, Neilson RP, Hansen L, Hannah L (2006) Global warming and extinctions of endemic species from biodiversity hotspots. Conserv Biol 20(2):538-548

Misson L, Rocheteau A, Rambal S, Ourcival JM, Limousin JM, Rodriguez R (2010) Functional changes in the control of carbon fluxes after 3 years of increased drought in a Mediterranean evergreen forest? Global Change Biol 16:2461-2475

Morin C, Samson J, Dessureault M (1999) Protection of black spruce seedlings against Cylindrocladium root rot with ectomycorrhizal fungi. Can J Bot 77(1):169-174

Morris MH, Smith ME, Rizzo DM, Rejmánek M, Bledsoe CS (2008) Contrasting ectomycorrhizal fungal communities on the roots of co-occurring oaks (Quercus spp.) in a California woodland. New Phytol 178:167-176

O'Dell TE, Ammirati JF, Schreiner EG (1999) Species richness and abundance of ectomycorrhizal basidiomycete sporocarps on a moisture gradient in the Tsuga heterophylla zone. Can J Bot 77:1699-1711

O’Neill GA, Hamann A, Wang T (2008) Accounting for population variation improves estimates of the impact of climate change on species' growth and distribution. J Appl Ecol 45:1040-1049

Quézel P, Médail F (2003) Ecologie et biogéographie des forêts du bassin méditerranéen. Elsevier, Paris, p 572

Richard F, Millot S, Gardes M, Selosse M-A (2005) Diversity and specificity of ectomycorrhizal fungi retrieved from an old-growth Mediterranean forest dominated by Quercus ilex. New Phytol 166(3):1011-1023

Richard F, Selosse M-A, Gardes M (2009) Facilitated establishment of Quercus ilex in shrub-dominated communities within a Mediterranean ecosystem: do mycorrhizal partners matter. FEMS Microbiol Ecol 68(1):14-24

Sardans J, Penuelas J (2005) Drought decreases soil enzyme activity in a Mediterranean Quercus ilex L. forest. Soil Biol Biochem 37 (3):455-461
Scarascia-Mugnozza G, Oswald H, Piussi P, Radoglou K (2000) Forests of the Mediterranean region. Gaps in knowledge and research needs. For Ecol Manag 132:97-109

Shi LB, Guttenberger M, Kottke I, Hampp R (2002) The effect of drought on mycorrhizas of beech (Fagus sylvatica L.): changes in community structure, and the content of carbohydrates and nitrogen storage bodies of the fungi. Mycorrhiza 12 (6):303-311

Smit E, Leeflang P, Gommans S, van den Broeck J, van Mil S, Wernars K (2001) Diversity and seasonal fluctuations of the dominant members of the bacterial soil community in a wheat field as determined by cultivation and molecular methods. Appl Environ Microb 67:2284-2291

Smith SE, Read DJ (2008) Mycorrhizal symbiosis, 3rd edn. Academic, London, p 815

Smith JE, Molina R, Huso MMP, Luoma DL, Mc KD, Castellano MA, Lebel T, Valachovic Y (2002) Species richness, abundance, and composition of hypogeous and epigeous ECM fungal sporocarps in young, rotation-age, and old-growth stands of Douglas-fir (Pseudotsuga menziesii) in the Cascade Range of Oregon, U.S.A. Can J Bot 80:186-204

Smith ME, Douhan GW, Rizzo DM (2007) Ectomycorrhizal community structure in a xeric Quercus woodland based on rDNA sequence analysis of sporocarps and pooled roots. New Phytol 174(4):847-863

Sthultz CM, Gehring CA, Kennedy K, Whitham TG (2009) Influence of herbivory and host plant genetics on the ectomycorrhizal fungal communities of a foundation tree. New Phytol 184: 657-667

Swaty RL, Deckert RJ, Whitham TG, Gehring CA (2004) Ectomycorrhizal abundance and community composition shifts with drought: predictions from tree rings. Ecology 85:1072-1084

Terradas J (1999) Holm oak and holm oak forests: an introduction. In: Roda F, Retana J, Gracia CA, Bellot J (eds) Ecology of Mediterranean evergreen oak forests. Springer, Berlin, pp 3-14

Thompson JD, Higgins DG, Gibson TJ (1994) Clustal-W-improving the sensitivity of progressive multiple sequence alignment through sequence weighting, position-specific gap penalties and weight matrix choice. Nucleic Acids Res 22(22):4673-4680

Valdes M, Asbjornsen H, Gomez-Cardenas M, Juarez M, Vogt KA (2006) Drought effects on fine-root and ectomycorrhizal-root biomass in managed Pinus oaxacana Mirov stands in Oaxaca, Mexico. Mycorrhiza 16:117-124

Visser S (1995) Ectomycorrhizal fungal succession in jack pine stands following wildfire. New Phytol 129:389-401

Walker JF, Miller OK, Horton JL (2005) Hyperdiversity of ectomycorrhizal fungus assemblages on oak seedlings in mixed forests in the southern Appalachian mountains. Mol Ecol 14:829-838 